\title{
04;05;06
}

\section{Влияние высокоэнтальпийного потока плазмы аргона на структуру и свойства нанокерамики $\mathrm{YBa}_{2} \mathrm{Cu}_{3} \mathrm{O}_{7-\delta}$}

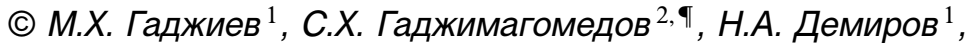 \\ Г.Б. Рагимханов ${ }^{2}$, В.С. Курбанисмаилов ${ }^{2}$, Д.К. Палчаев ${ }^{2,3}$, \\ Ж.Х. Мурлиева ${ }^{2}$ \\ ${ }^{1}$ Объединенный институт высоких температур, Москва \\ ${ }^{2}$ Дагестанский государственный университет, Махачкала \\ ${ }^{3}$ Южный федеральный университет (филиал), Махачкала \\ ๑ E-mail: darkusch@mail.ru
}

Поступило в Редакцию 27 января 2017 г.

Приведены результаты исследований структуры и электросопротивления наноструктурированной керамики на основе $\mathrm{YBa}_{2} \mathrm{Cu}_{3} \mathrm{O}_{7-\delta}$ до и после воздействия высокоэнтальпийным потоком плазмы аргона. Показана возможность упрочнения межзеренных связей в приповерхностном слое этой керамики и изменения индекса кислородной стехиометрии в результате обработки плазменной струей.

DOI: 10.21883/PJTF.2017.13.44808.16719

Функциональные высокотемпературные сверхпроводящие (ВТСП) материалы используются [1-3] в различных отраслях современной техники: электронике, вычислительной технике, медицине, энергетике, транспорте. Рассматривается [4,5] перспектива использования этих материалов в космической технике, поскольку в условиях космоса не требуется охлаждающих устройств, что значительно снижает геометрические размеры и массу соответствующей аппаратуры. В микрокристаллических керамических образцах $\mathrm{YBa}_{2} \mathrm{Cu}_{3} \mathrm{O}_{7-\delta}$ в результате снижения сил межатомного взаимодействия на контактах между сверхпроводящими зернами значение критического тока снижается на порядки. На прочность этих контактов влияют также термические напряжения, связанные с образованием дефектов и пор на поверхности микрокристаллических зерен образцов в процессе спекания керамики. При наноструктурировании материала свойство снижения прочности межзеренных связей усугубляется. С другой стороны, уменьшение 
размеров кристаллических зерен снижает эффект возникновения термических напряжений при спекании, а наличие наноразмерных дефектов структуры эффективно способствует [6-8] пиннингу вихрей. Как известно [8], плазменная обработка ВТСП-керамики приводит к аморфизации поверхности образцов и снижению доли дефектов на межзеренных границах, обеспечивая защиту образцов от деградации их сверхпроводящих свойств. Заметим также, что разработка технологий получения ВТСП с высокими значениями плотности критического тока $\left(j_{c}\right)$ и температуры сверхпроводящего перехода $\left(T_{c}\right)$ для поликристаллических образцов различного состава, помимо прочего, предполагает формирование соответствующей структуры. Работы по повышению критических параметров $\left(j_{c}\right.$ и $\left.T_{c}\right)$ ведутся в направлениях: совершенствования структуры сверхпроводящих слоев [9]; создания искусственных центров пиннинга с использованием примесей или нанодобавок [10]; создания дефектов кристаллической структуры под действием радиационных излучений [3], воздействия плотной импульсной плазмой [8,11], а также протонным излучением [12]. Последние проводятся с целью повышения эффективности передачи соответствующей энергии обрабатываемому материалу.

В настоящей работе представлены результаты исследований структуры и свойств наноструктурированной керамики на основе $\mathrm{YBa}_{2} \mathrm{Cu}_{3} \mathrm{O}_{7-\delta}$ до и после воздействия высокоэнтальпийного плазменного потока. Поверхность наноструктурированной керамической мишени состава $\mathrm{YBa}_{2} \mathrm{Cu}_{3} \mathrm{O}_{7-\delta}$, предназначенной для получения пленок методом магнетронного распыления, подвергалась воздействию высокоэнтальпийной плазменной струи, создаваемой плазмотроном постоянного тока с расширяющимся каналом выходного электрода [13]. В качестве плазмообразующего газа использовался аргон и смесь аргон-кислород. Принимая во внимание, что свойства ВТСП-материалов на основе $\mathrm{YBa}_{2} \mathrm{Cu}_{3} \mathrm{O}_{7-\delta}$ очень чувствительны к стехиометрии по кислороду, воздействие на образцы аргоновой плазменной струи осуществлялось в атмосфере воздуха. Результаты таких исследований необходимы для разработки технологий упрочнения межзеренных связей в наноструктурированной керамике и получения покрытий на основе $\mathrm{YBa}_{2} \mathrm{Cu}_{3} \mathrm{O}_{7-\delta} \mathrm{c}$ высоким индексом кислородной стехиометрии.

Испытуемый наноструктурированный керамический материал на основе $\mathrm{YBa}_{2} \mathrm{Cu}_{3} \mathrm{O}_{7-\delta}$, был получен в один этап спекания методом [14,15], который обеспечивал формирование структуры с необходимой плот-

Письма в ЖТФ, 2017, том 43, вып. 13 
ностью и оптимальное насыщение кислородом. Однако при наноструктурировании прочность межзеренных связей в этих материалах оказывается ниже, чем для микрокристаллической керамики, полученной по обычной технологии. Дифракционный анализ и исследования фазового состава образца до и после воздействия плазменного потока проводился на дифрактометре PANalytical Empyrean series 2 и сканирующем электронном микроскопе LEO-1450 с EDX-анализатором INCA Energy соответственно. Размер кристаллитов определялся по формуле Шеррера. Исследования спектров комбинационного рассеяния проводились на атомно-силовом микроскопе Ntegra Spectra (NT-MDT) (режим комбинационного рассеяния). Измерения электросопротивления проводились стандартным 4-зондовым методом с использованием цифрового мультиметра Keithley 2002 на автоматизированной установке.

В качестве источника низкотемпературной высокоэнтальпийной плазмы использовался плазмотрон с расширяющимся каналом выходного электрода [16-18]. Плазмотрон генерирует слаборасходящуюся $\left(2 \alpha=12^{\circ}\right)$ плазменную струю аргона или смеси аргон-кислород диаметром $D=5-8 \mathrm{~mm}$ с энтальпией $5-10 \mathrm{~kJ} / \mathrm{g}$ и среднемассовой температурой 5-10 kK при полной электрической мощности дугового разряда $5-15 \mathrm{~kW}$ и расходе плазмообразующего газа $1-3 \mathrm{~g} / \mathrm{s}$. Оценка параметров плазмы (температуры $T_{e}$ и концентрации электронов $n_{e}$ ) производилась по данным анализа спектров, полученных трехканальным оптоволоконным спектрометром AvaSpec 3648 со спектральным разрешением $0.2-0.5 \mathrm{~nm}$ в диапазоне $220-1100 \mathrm{~nm}$. Удельные тепловые потоки $q$ определялись по результатам калориметрических измерений тепловых потоков плазменной струи, поступающей на поверхность многосекционного торца медного калориметра. Видеонаблюдение за взаимодействующей системой „набегающий высокоэнтальпийный плазменный поток-сублимирующий термостойкий образец“ проводилось высокоскоростной камерой Phantom Miro M110, которая в масштабе $1: 3$ обеспечивала регистрацию изображения области взаимодействия „струя-исследуемый образец“ в течение всего периода наблюдения с пространственным разрешением около $25 \mu \mathrm{m}$. Температура поверхности образца определялась путем периодического помещения перед объективом камеры интерференционного фильтра $589 \mathrm{~nm} \mathrm{c} \mathrm{полосой} \mathrm{про-}$ пускания $\delta \lambda_{1 / 2}=10 \mathrm{~nm}$, что позволяет использовать высокоскоростную камеру в качестве быстродействующего пирометра [19]. Концентрация электронов в приосевой области плазменной струи оценивалась по полуширине линий $\mathrm{H}_{\alpha}$ и $H_{\beta}$ с последующим сравнением с соответству-

Письма в ЖТФ, 2017, том 43, вып. 13 

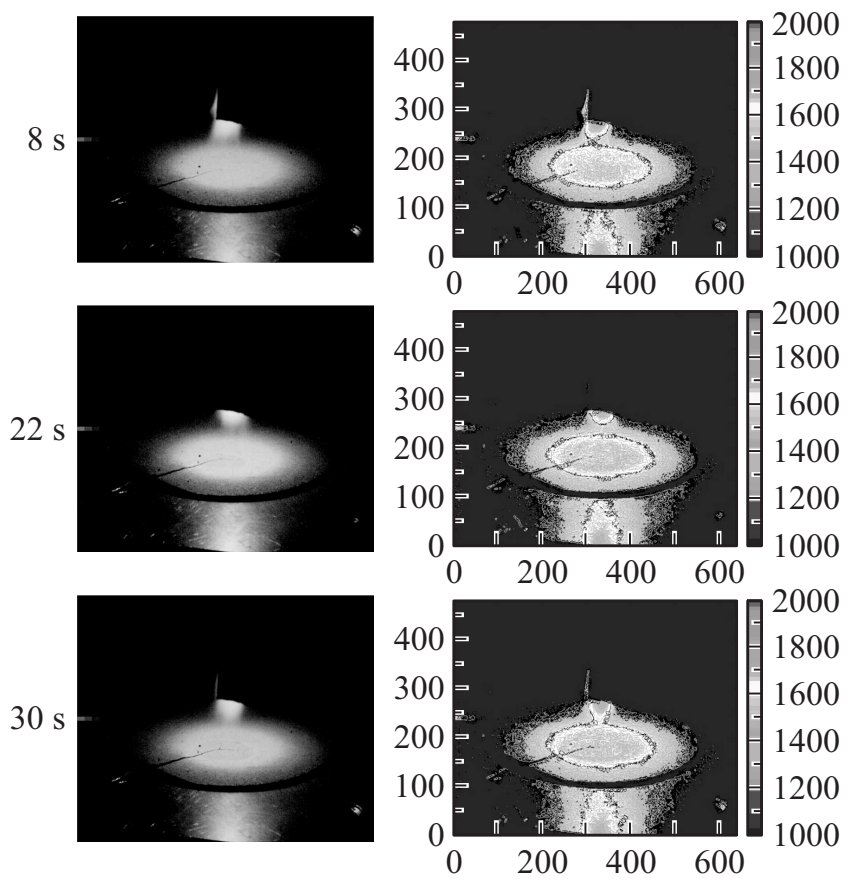

Рис. 1. Фотографии свечения образца в разные моменты времени и его преобразование в поле температур.

ющими уширениями линий из работы Конжевика [20]. Оценки показали, что при токе $250 \mathrm{~A}$ значения температуры и концентрации электронов в приосевой плазме аргона на срезе сопла составляли $T_{e}=12 \mathrm{kK}$, $n_{e}=10^{17} \mathrm{~cm}^{-3}$, а на расстоянии $20 \mathrm{~mm}$ от среза $T_{e}=10.5 \mathrm{kK}$, $n_{e}=10^{16} \mathrm{~cm}^{-3}$. Скорость плазменного потока определялась по значениям полного давления с помощью трубки Пито, представлявшей собой изогнутую капиллярную трубку, заключенную в медный корпус, охлаждаемый проточной водой [21]. Скорости плазменной струи на расстоянии 0-20 mm от среза сопла при токе 250 А и расходе газа $3 \mathrm{~g} / \mathrm{s}$ составляли $1000-450 \mathrm{~m} / \mathrm{s}$ соответственно. При оценках этих скоростей учитывались зависимости удельной теплоемкости, показателя адиабаты и скорости звука от температуры $[22,23]$. Конструкция плазмотрона позволяет распылять порошки, направляемые в плазменную струю.

Письма в ЖТФ, 2017, том 43, вып. 13 


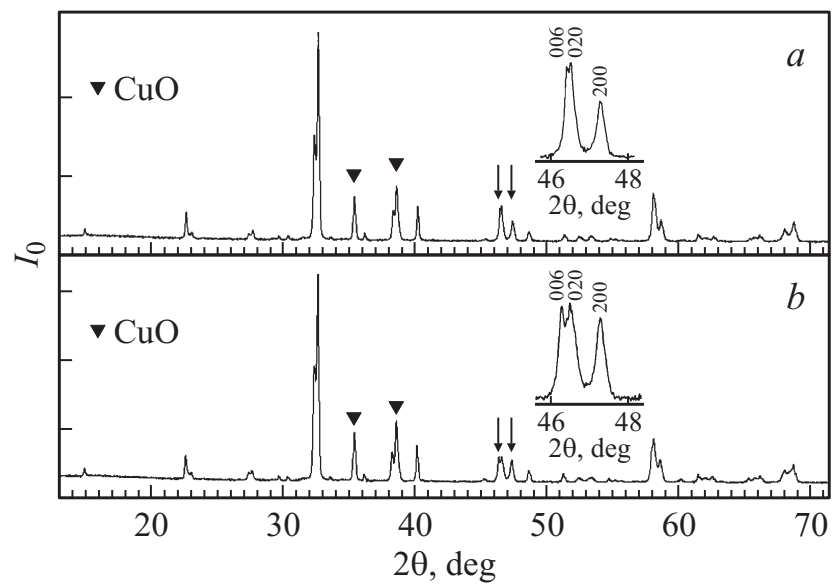

Pис. 2. Дифрактограммы наноструктурированных ВТСП-мишеней на основе $\mathrm{YBa}_{2} \mathrm{Cu}_{3} \mathrm{O}_{7-\delta}$, полученной термической обработкой порошка при $623 \mathrm{~K}$ в течение $1 \mathrm{~h}$ : до $(a)$ и после $(b)$ воздействия потока плазмы.

Воздействие на образец высокоэнтальпийной плазменной струей аргона при токе $250 \mathrm{~A}$ и расходе $3 \mathrm{~g} / \mathrm{s}$ осуществлялось на расстоянии $20 \mathrm{~mm}$ от среза сопла плазмотрона в течение $\sim 60 \mathrm{~s}$. На рис. 1 приведены фотографии свечения плазмы и образца, соответствующие различным моментам времени, полученные при съемке высокоскоростной видеокамерой. Для оценки изменения яркостной температуры поверхности образца со временем было выполнено программное преобразование распределения температурных полей. Результаты такой оценки приведены на рис. 1 (справа). Регистрируемые свечения образца калибровались по яркости эталонного источника излучения (вольфрамовая лампа с яркостной температурой в $2400 \mathrm{~K}$ ). Анализ результатов скоростной съемки и термограмм показал, что за короткое время, $4-5 \mathrm{~s}$, температура в эпицентре плазменной струи достигает $\sim 1600 \mathrm{~K}$, образец вне эпицентра нагревается до $1400 \mathrm{~K}$ всеми видами теплопередачи. Завышенная температура по краям образца, а также свечение ниже образца на термограммах связаны с отражением свечения плазмы от поверхности медного калориметра.

На рис. 2, a приведена дифрактограмма нанокерамики на основе $\mathrm{YBa}_{2} \mathrm{Cu}_{3} \mathrm{O}_{6.9}$ до воздействия потоком плазмы. Наличие оксида меди

Письма в ЖТФ, 2017, том 43, вып. 13 


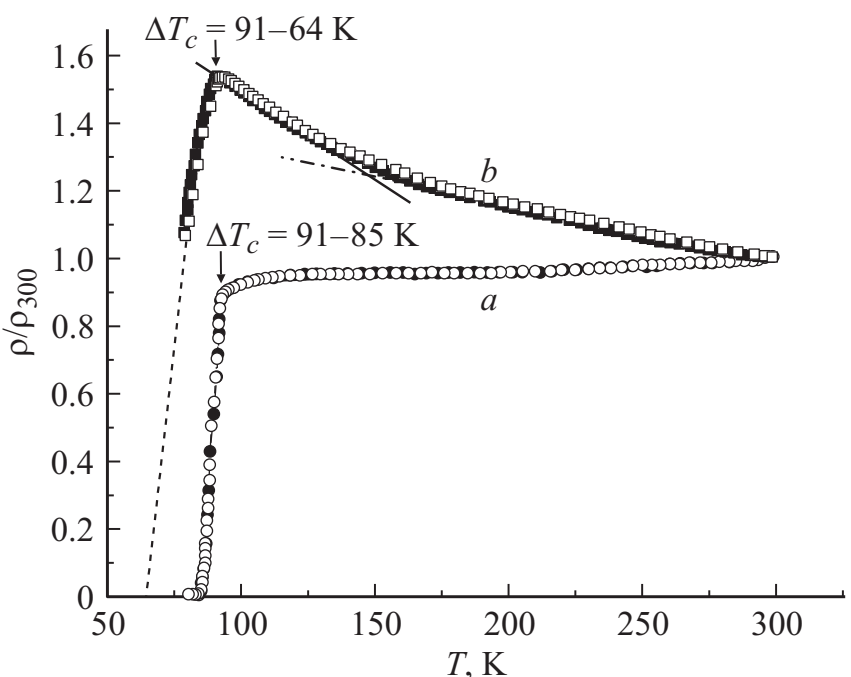

Рис. 3. Температурные зависимости электросопротивлений $\mathrm{YBa}_{2} \mathrm{Cu}_{3} \mathrm{O}_{7-\delta}$-мишеней, полученных термической обработкой порошка при $623 \mathrm{~K}$ в течение $1 \mathrm{~h}$ : до $(a)$ и после $(b)$ воздействия потока плазмы.

(рис. 2) в кристаллическом состоянии свидетельствует о возможности существования в ней рентгеноаморфных оксидов, обедненных медью, равномерное распределение которых обычно повышает [14] значения критического тока. На рис. 2, $b$ приведена дифрактограмма того же образца после воздействия на него потоком плазмы. Изменения претерпело значение кислородной стехиометрии этого образца, о чем свидетельствует более отчетливый рефлекс 006 (см. вставки на рис. 2, a и $b$ ). Индекс при кислороде в приповерхностном слое снизился до 6.66. Воздействие потоком плазмы привело также к небольшим изменениям плотности образца и среднего размера кристаллитов (от $3.5 \mathrm{~g} / \mathrm{cm}^{3}$ и $72 \mathrm{~nm}$ до $3.8 \mathrm{~g} / \mathrm{cm}^{3}$ и $74 \mathrm{~nm}$ соответственно). Эти изменения произошли за счет приповерхностного слоя.

На рис. 3 приведены результаты исследования электросопротивления до и после воздействия плазмой. Температура начала перехода в сверхпроводящее состояние у этих образцов не изменилась и составляет $\sim 91 \mathrm{~K}$. Ход температурной зависимости электросопро-

Письма в ЖТФ, 2017, том 43, вып. 13 
тивления после воздействия плазмой изменился с металлического на полупроводниковый, а интервал $\left(\Delta T_{c}\right)$ перехода - с 6 до $25 \mathrm{~K}$. Абсолютные значения электросопротивления оказались выше почти в два раза, что указывает на снижение индекса кислородной стехиометрии после воздействия потоком плазмы. Воздействие на образец потоком плазмы приводит к модификации лишь его приповерхностного слоя в виде уплотнения, рекристаллизации и снижения индекса кислородной стехиометрии. Очевидно, что это снижение было связано с тем, что плазменная струя создавалась аргоном. В работе [24] было показано, что выбор в качестве рабочего газа смеси $\mathrm{Ar} / \mathrm{O}_{2}$ позволяет получать пленки $\mathrm{YBa}_{2} \mathrm{Cu}_{3} \mathrm{O}_{7-\delta}$ с высоким содержанием кислорода магнетронным распылением наноструктурированной керамической мишени. На увеличение содержания кислорода в микрокристаллических образцах $\mathrm{YBa}_{2} \mathrm{Cu}_{3} \mathrm{O}_{7-\delta}$ после многочасовой обработки плотной импульсной плазмой кислорода указывалось в работе [8]. Для наноструктурированных материалов время воздействия непрерывным потоком плазмы, очевидно, должно снизиться.

Разработанная нами технология позволяет получать наноструктурированную керамику на основе $\mathrm{YBa}_{2} \mathrm{Cu}_{3} \mathrm{O}_{7-\delta}$ с плотностью в пределах от 3 до $6 \mathrm{~g} / \mathrm{cm}^{3}$ путем соответствующей термообработки исходного порошка прекурсора. Повышение прочности межзеренных связей в изделиях из этой керамики может быть осуществлено плазменной обработкой. Исходный индекс кислородной стехиометрии образца и его электрические свойства в упрочненном приповерхностном слое можно сохранить воздействием потоком аргон-кислородной плазмы определенной концентрации.

Работа выполнена при финансовой поддержке Государственных заданий № 2560, № 16.1103.2014/К, 3.5982.2017/8.9.

\section{Список литературы}

[1] Романовский В.Р. // ЖТФ. 2015. Т. 85. В. 1. С. 87-97.

[2] Дроздов Ю.Н., Мастеров Д.В., Павлов С.А. и др. // ЖТФ. 2015. Т. 85. В. 11. C. $109-116$.

[3] Rudnev I., Podlivaev A. // IEEE Trans. Appl. Supercond. 2016. V. 26 (4). P. 8200104-4.

[4] http://nuclphys.sinp.msu.ru/school/s11/11_05.pdf.

[5] Мухортов Вл.М., Следков В.А., Мухортов В.М. // Микросистемная техника. Ч. I. 2002. № 8. С. 20-24. 
[6] Терентьев К.Ю., ГохФельд Д.М., Попков С.И. и др. // ФТТ. 2011. Т. 53. В. 12. C. 2289-2293.

[7] Fratini M., Poccia A., Ricci A. et al. // Nature. 2010. V. 466. P. 841-844.

[8] Позигун С.A., Пан В.М., Алексеев В.А. и др. // Usp. Fiz. Met. 2004. V. 5. P. 167.

[9] Гапонов С.В., Гусев С.А., Дроздов Ю.Н. и др. // ЖТФ. 2014. Т. 84. В. 10. C. 68.

[10] Rejith P.P., Vidya S., Thomas J.K. // Materials Today: Proc. 2015. V. 2. P. $997-$ 1001.

[11] Bagley B.G., Greene L.H., Tarascon J.-M. et al. // Appl. Phys. Lett. 1987. V. 51. P. 622.

[12] Антонова Л.Х., Демихов Т.Е., Троицкий А.В. и др. // Перспективные материалы. 2014. V. 5. Р. 34.

[13] Гаджиев М.Х., Тюбтяев А.С., Саргсян М.А. и др. // Вестник ДГУ. Серия 1. Естественные науки. 2016. Т. 31(1). С. 22.

[14] Гаджимагомедов С.Х., Палчаев Д.К., Рабаданов М.Х. и др. // Письма в ЖТФ. 2016. Т. 42. В. 1. С. 9-15.

[15] Шабанов Н.С., Гаджимагомедов С.Х., Палчаев Д.К. и др. // Патент RU № 2601073. 02.06.2016.

[16] Gadzhiev M.Kh., Tereshonok D.V., Tyuftyaev A.S. // EPL. 2015. V. 111. P. 25001.

[17] Гаджиев М.Х., Исакаев Э.Х., Тюбтлев А.С. и др. // Письма в ЖТФ. 2016. T. 42. B. 2. C. 44-49.

[18] Исакаев Э.Х., Тюбтяев А.С., Гаджиев М.X. // Физика и химия обработки материалов. 2016. Т. 3. С. 27.

[19] Горячев С.В., Исакаев Э.Х., Мясников М.И. и др. // ТВТ. 2008. Т. 46. В. 6. C. 1 .

[20] Lesage A., Fuhr J. Konjevic N. et al. // J. Phys. Chem. Ref. Data. 2002. V. 31(3). P. 819.

[21] Gadzhiev M.Kh., Kulikov Y.M., Panov V.A. et al. // High Temperature. 2016. V. 54(1). P. 38.

[22] Дресвин С.В., Иванов Д.В. // Физика плазмы: Учеб. пособие. СПб.: Изд-во Политехнического ун-та. 2013. $544 \mathrm{c}$.

[23] Kian Eisazadeh-Far, Hameed Metghalchi, James C. Keck. // J. Energy Res. Technol. 2011. V. 133. P. 022201.

[24] Гамматаев С.Л., Хашаба А.Х.Д., Палчаев Д.К. // Вестник ДгУ. 2015. Т. 30. B. 6. C. 14-20.

3 Письма в ЖТФ, 2017, том 43, вып. 13 